\title{
Improvement of Traceability of Widely-Defined Measurements in the Field of Humanities
}

\author{
K. Sapozhnikova, R. Taymanov \\ D.I. Mendeleyev Institute for Metrology (VNIIM) 19, Moskovsky pr., 190005, St.Petersburg, Russia, \\ e-mail: k.v.s@vniim.ru, taymanov@vniim.ru
}

In the last decades, a tendency to extend the domain of "fuzzy" measurements of multiparametric quantities to the field of humanities has been observed. In the measurement process, the "fuzzy" measurements should meet the requirements of metrological traceability. The paper deals with the approach proposed for developing a measurement model of "fuzzy" measurements. The approach suggested is illustrated by an example of a model for measuring the emotions contained in musical fragments. The model is based on the hypothesis that permits to explain the origination of emotions in the evolution process.

Keywords: Traceability, multiparametric measurand, measurement model, music perception, infrasound

\section{INTRODUCTION}

$\mathrm{L}$ AST DECADES in the field of humanities have been marked by an evident tendency to intensify measurements performed with measuring instruments. As a rule, the corresponding measurands are multiparametric [1] - [6]. These measurands refer to the properties of material objects such as taste or odour, as well as to the psycho-physiological features of people such as their ability to keep in mind and recognize emotional content of artworks or literature, etc. Examples of similar tasks of the "fuzzy" measurements can be found in the EU project "Measuring the Impossible". In many cases, such measurements have the following feature: at first, the availability of some property is determined (e.g., the presence of orange odour), then a quantitative estimate of intensity and additional characteristics are given.

In order to make measurement results comparable, it is necessary to provide the metrological traceability of these results, i.e.:

- to provide the possibility of relating a measurement result to a reference which is specified and available for measuring or reproducing,

- to accompany a measurement result with evaluation of its uncertainty.

In the general case, the requirement of metrological traceability can be interpreted as the need to have:

- measurement model grounded for the conditions of a task being solved;

- appropriate function $Y=f\left(\alpha_{1}, \quad \alpha_{i} \quad \ldots \alpha_{k}\right)$, linking measurand $Y$ with measured parameters $\alpha_{i}$,

where $k$ is the number of various parameters, $1<i \leq k$ (it is desirable to minimize the number of various $k$ - parameters at a required accuracy of the model);

- reference for comparison, established for each parameter being measured. The reference "can be a definition of a measurement unit through its practical realization, or a measurement procedure..., or a measurement standard" [7].
An uncertainty value estimate in measuring $Y$ consists of both a definitional uncertainty caused by some inaccuracy of the proposed measurement model and uncertainty of $\alpha_{i}$.

The multiparametric measurements are rather widely spread. During many years, they have been often used in order to identify substances, to measure colour, to diagnose machines, etc. In principle, the development of the corresponding measurement models is not too difficult.

Measurements in the domain of humanities are connected with the necessity to solve significant problems, because in many cases all proposed measurement models are of a phenomenological nature, i.e. they depend upon subjective ideas. Therewith, an experimental proof of their effectiveness (for the required field of application) is timeconsuming and causes significant expenses. (Efficiency of a measurement model is inversely proportional to a definite uncertainty).

Usage of the phenomenological measurement model grounded for measurements in a narrow domain, can lead to serious mistakes outside the limits of this domain, which cannot be strictly controlled in many cases. For example, estimation of the recruit health on the basis of the results of a legal procedure of medical examination ignores a probability of rare diseases.

To decrease the amount of research work and probability of crude errors, it is expedient to seek a widely-defined measurement model relying on physical, biological, sociological, economical or other regularities (depending on the field of measurements). In this case, the probability to reveal the most significant $\alpha_{i}$ can be increased. It is necessary to measure $\alpha_{I}$ values according to the established measurement procedures. They should have a reference for comparison.

The efficiency of such an approach can be demonstrated using the development of a "fuzzy" measurement model for determining various emotional responses to music fragments (or other acoustic fragments). Solving this problem will be useful for music theory, creation of new musical instruments, automatic translation of speech, and a lot of other applications. 


\section{THE MODEL FOR MEASUREMENTS OF EMOTIONAL RESPONSE OF A LISTENER}

\section{A. The hypothesis proposed}

Emotions arise in an individual in the course of perceiving the reality, i.e. life. Information generates some emotions, and corresponding information is transferred by emotions too. According to [8], the emotions motivate, organize and guide the perception, thought, and actions.

Generally, in the models used for measuring emotions, panel or jury testing methods are applied. In some cases, such measurements are accompanied by an analysis of biophysical parameters of listeners. The measurements of this type permit to evaluate a response of "testees" a posteriori. These measurement results contribute to a better understanding of general regularities of emotion origination.

The emotions accompanying the human perception of acoustical impacts can be estimated a priori only with the help of measurements of a set of parameters characterizing these impacts. For the corresponding measurement model, the most distinguished parameters $\alpha_{i}$ could be the parameters similar to those characterizing physiological processes, e.g. frequency of a process, its intensity, etc.

To develop such a measurement model, the authors have proposed a hypothesis and briefly grounded it in [9]-[13]. Any acoustical impact carrying emotional information contains signal-stimuli, the perception and recognition of which in the corresponding sequence cause generation of emotions. In its turn, each of these signal-stimuli can be characterized either by one parameter or by a number of them. The parameters of the signal-stimuli can be measured and related to the known measurement units.

In other words, for such a model the emotion $Y\left(\alpha_{i}\right)$ can be expressed as:

$Y=f\left[X_{1}\left(\alpha_{1}, \alpha_{i} \ldots \alpha_{k}\right), X_{2}\left(\alpha_{1}, \quad \alpha_{i} \ldots \alpha_{k}\right), ., X_{m}\left(\alpha_{1}, \alpha_{i} \ldots \alpha_{k}\right)\right]$, where:

$X_{1}, X_{2, \ldots} X_{m}$ are the signal-stimuli;

$m$ is the number of various signal-stimuli generating a complete set of the emotions examined.

In the process of measuring the emotions which are present in acoustical impacts, solution of the problem to develop a model can be brought to revealing both the above signal-stimuli and parameters characterizing them.

First of all, it is necessary to prove the availability of a relationship between the model parameters and listeners' expected response to the corresponding acoustic impact. To develop a model, the evolutionary analysis of appropriate sensor systems [14] - [17] was applied. (All the references are illustrative rather than exhaustive.)

Living creatures have acquired sensor systems to provide themselves with the ability to adapt to changes of the environment. The sensor systems became means contributing to perceiving signals (cues) which stimulated readiness for actions connected with approaching natural disasters, enemies, as well as "food" or male (female) animals.

Here the term "signal" means a change in the environment, which takes place within a rather short time period, e.g. a roar, blow, light flash.
For living creatures that left the ocean and settled on land, a system providing the sense of touch became the most important sensor system. The sense of touch is related to the ability to perceive medium pressure changes (waves) caused, for example, by an earthquake or a moving body. Since the auditory ability is the ability to perceive pressure variations (waves) in air, it is possible to make a conclusion that a foretype of the auditory system originated at the earliest stages of life formation. The sense of touch is inherent in the majority of living creatures.

The natural selection caused the genesis of unconditioned reflexes of living creatures, including those with a weakly developed nervous system. These reflexes are related to responses to certain changes of environmental pressure and became foretypes of emotions.

In particular, it is known that an approaching tsunami generates waves within the infrasound frequency range and in a lower part of the sound frequency range. (Hereinafter, the above ranges will be referred to as the IFR). These waves propagate in water and give rise to a specific behaviour of living inhabitants of seas and oceans, including medusas, i.e. their attempt to escape. To a certain degree, a similar response is typical for animals living on land. This effect can be explained as follows.

When reptiles left water and settled on land where the density of the environment around a large part of their bodies became significantly lower, their sensitivity to the IFR waves giving danger signals decreased.

The necessity for reptiles to keep their ability to perceive IFR information of vital importance has resulted in the appearance of more developed hearing aids. The living creatures gained the possibility to perceive the IFR waves both directly and indirectly by using:

- tactile system perceiving mechanical IFR waves and

- "ear-brain" system perceiving air waves of the sound frequency range (SFR) and then recognizing the corresponding IFR waves in some way. (The SFR is limited for man by a range of approximately (14-16) $\mathrm{Hz}-16 \mathrm{kHz}$, as for other living creatures with the ability to hear, these limits can be a little bit shifted.)

There are many examples which prove that animals perceive IFR waves as cues carrying emotions [18] - [25]. The well-known experiments, including those performed by Dr. R. Wood [26], have shown that IFR waves can cause panic, i.e. they are emotionally important for a man too.

The IFR waves of a specific amplitude and frequency are the signal-stimuli which define an elementary emotional response. This response is an emotional stress that prepares some subsequent action. It precedes the sense of fear, aggression, or happiness, depending on additional information.

A response to important signal-stimuli is determined, to a great extent, by closeness of their frequency values to the frequency of biorhythms [11]. Emotions of living creatures at the first stage of their existence were associated with danger threatening an individual organism (negative emotions). Therefore, the first emotions of living creatures were negative rather than positive ones. The majority of sounds the animals emit are actually caused by negative emotions [27], [28]. 
The genesis of a community (a swarm, flock, pack, or family) has given rise to a need of a member of such a community to transfer information to other members of the community, which can be negative due to an alarm emotion, positive due to availability of food or a victory gained in struggle for survival, or even neutral (acoustic identification of male or female animal). The development of human society is connected with a more noticeable differentiation of situations and more developed palette of emotional responses.

When the number of the IFR wave parameters is extremely small, a single way for an animal or a man to enrich emotional information being transferred is to create emotional images using small groups (ensembles) of signalstimuli, and then to produce more substantial information (emotional content) integrating a sequence of such images. Such a structure resembles a speech structure with a limited number of sounds, incommensurably wider set of words and practically the unlimited possibility to transfer substantial logical information.

According to the famous biologist Prof. Dolnik, the CroMagnon man (unlike the Neanderthal man) survived because he managed to enrich the emotional SFR waves he used, having put into them an emotionally rich logical content: he learned the art of speech [29]. Prof. Mithen has also come to this idea [30].

Therefore, the frequency and level of the IFR signalstimuli (or some other parameters similar to them) can be accepted as parameters $\alpha_{1}$ and $\alpha_{2}$ of the basic measurement model of emotions contained in acoustical impacts, while groups containing a sequence of signal-stimuli can be used as emotional images.

For this model, a mechanism for selecting signal-stimuli from air waves of the SFR is explained below.

As it is known, when the conversion function of a converter is non-linear, an output signal spectrum becomes "richer" than an input one. If the input signal spectrum includes waves of two or more main frequencies, in the spectrum of output signals some intermodulation products are formed [31] - [34].

An intermodulation component of the spectrum at the output of the non-linear converter is characterized by its frequency $f_{k}$ and order $p_{k}$. The frequency of the intermodulation component is described by (1):

$$
f_{k}=\left|\sum_{i=1}^{m} n_{i} f_{i}\right|,
$$

where $n_{i}$ is the positive or the negative integer, or $n_{i}=0$; $f_{k}$ are the frequency values related to input interactive waves; $m$ is the number of input interactive waves of different frequencies.

The order $p_{k}$ is the sum of sequence numbers of the harmonics which interact, generating the intermodulation component. It is described by (2):

$$
p_{k}=\sum_{i=1}^{m}\left|n_{i}\right|
$$

With increase of the order, the amplitude of combination component decreases quickly, but irregularly, because the amplitude value depends also on the fact whether $p_{k}$ is even or odd. Subject to the polynomial coefficient describing the nonlinearity of the converter, usually an additional suppression of the even or odd order intermodulation components takes place. However, in practice, this effect can be seen only at comparably small values of $p_{k}$. (approximately up to $p_{k}=5$ ).

As the authors suppose, in an "ear-brain" system, the acoustic SFR waves of some frequencies are memorized and nonlinearly converted. After that, the IFR intermodulation components which give rise to a vitally important response are selected from the output signal spectrum [12].

The basic model being considered is the most important part of the model for measuring emotions "contained" in acoustic impacts.

However, in accordance with the above idea of the sensor system evolution, the basic measurement model for mammals, including humans, should be supplemented by a linear converter of acoustic waves. This converter identifies the parameters of emotions originating much later, including those related to the development of communication between living creatures with the help of acoustic signals. At the same time, in applying this model, it should be taken into account that the level and frequency of signals emitted by mammals increase with an increase of emotional excitement $[27,35,36]$. This effect can be explained by the fact that with an increase of the level and frequency of a SFR signal (e.g. an alarm signal calling for help), the radius of its propagation increases. This radius should be greater for a weak animal to survive.

The grounds of developing the described measurement model on the basis of biological evolution are confirmed by observations of mutual understanding of an emotional state by mammals and man [27], [35], [36], [38].

\section{B. Calculation method}

To verify the proposed hypothesis and basic model of emotion measurement, the calculations of the parameters of intermodulation components arising in a non-linear converter, were performed. The intermodulation products were obtained as a result of interaction of the simplest sets of acoustic waves.

For such sets, the reference (basic) elements of musical tonalities were used.

Classical tonal music applies major and minor keys. The sound scale of a modern equal tempered tune (12-tone equal temperament) overlaps by 9 octaves the range from 16.35 $\mathrm{Hz}$ to $7902.13 \mathrm{~Hz}$ [39]. Only single samples of an organ reproduce the sounds of organ music beginning from $8 \mathrm{~Hz}$. To present day, in addition to the equal tempered tuning, the ancient Pythagorean tuning is applied [39] - [45]. In spite of its well-known drawbacks, it enables to achieve a greater expressiveness of musical phrases. It is logical, that vocalists and musicians playing the instruments with a changing pitch, often "tweak" the tuning in real performances, away from equal temperament [42], [43].

The basic elements of musical tonalities are tonic thirds and triads [44] - [48]. 
In [49], it is proved by experiments that some chords (intervals) consisting of two sine waves, including tonic thirds, are identified as emotionally coloured (they have emotional meaning). This is particularly true for the professional musicians. However, the emotional judgments of the intervals are also reliable for "amateurs" (who have learned to play an instrument since childhood) and, to a lesser degree, for "naive" listeners (who have never been taught to play any musical instrument). It follows from this statement that a set of intervals, e.g. a triad, has an emotional colour too. Such a conclusion corresponds to the point of view given in [50]. The author of [50] considers the tonic triads and thirds as having an emotional colour.

The third is built of two notes. The major tonic third includes tonality steps I (a tonic) and III, while the minor tonic third includes steps I and -III, where "_" means the semitone decrease of a step. Step III (for the major tonalities) and step -III (for the minor tonalities) mainly determine the key colour [44]- [46], [48], [49].

The tonic triad for any tonalities is a chord consisting of three notes. The lowest of these notes is a tonic (step I). The tonic triad includes steps I, III and V for the major tonalities, as well as steps I, -III and V for the minor tonalities [46], [48], [51]. For example, the $\mathrm{C}$ major tonic triad consists of notes $\mathrm{C}, \mathrm{E}$, and $\mathrm{G}$, while the $\mathrm{C}$ minor tonic triad consists of notes $\mathrm{C}$, E flat, and $\mathrm{G}$.

If the infrasound frequency range is limited by the frequency of $14 \mathrm{~Hz}$ from above, then it is easy to prove that in a lower part of the great octave, in the contra and subcontra octaves, the tonic third and triad frequency differences are in the IFR. Since formation of such IFR intermodulation components (the second order components) is typical both for the major and minor, these octaves are non-informative. (Since the boundaries of infrasound frequencies have been chosen approximately, the boundaries of a "non-informative" part of the range are approximate too).

If we consider the tonic thirds and triads in a higher part of the second octave and even in the next octaves, then for these thirds and triads only the high order intermodulation products in IFR can be obtained (their amplitude will be very small), i.e. the infrasound waves practically disappear from the intermodulation spectrum in these octaves.

Therefore, the calculations have been made for chords with frequencies related to the small, first and second octaves. These chords were simulated on the basis of harmonic (sine) waves in twelve major and twelve minor tonalities using the equal tempered tuning and the Pythagorean one. For dominating regularities to be revealed, appropriate sharp and flat tonalities were considered as being enharmonically equivalent. The frequency of note $\mathrm{A}$ in the first octave was equal to $440 \mathrm{~Hz}$.

In the investigation, the original method of calculation [52] - [54], which is a part of the methodology of frequency converter analysis and synthesis, developed by one of the authors of this paper, was applied. The method relies on the theory of continued fraction (chain sequence).

The intermodulation product parameters $\left(f_{k}\right.$ and $\left.p_{k}\right)$ were separately calculated for tonic thirds and triads of the equal tempered tuning and Pythagorean one.

\section{RESULTS}

\section{A. Signal-stimuli}

The calculation has shown that on interaction in a nonlinear converter, the sine waves included in the major tonic thirds (for both the equal tempered and Pythagorean tuning), generate the intermodulation components of the infrasound frequency range (from $5 \mathrm{~Hz}$ and higher). These components are characterized by the ninth order $(p=9)$.

For the minor tonic thirds, the infrasound intermodulation products (from $7 \mathrm{~Hz}$ and higher) have a higher order $(p=11)$, i.e. they are of a significantly lower level.

This difference between the major and minor tonalities is much more observable for the tonic triads.

For all major tonalities, at the output of the non-linear converter, the waves corresponding to the tonic triads produce the infrasound intermodulation components with $p=4$ (from $2.8 \mathrm{~Hz}$ and higher). In the minor tonic triads, the infrasound intermodulation components with $p=4$ are not generated. For the major and minor tonalities of the equal tempered tuning, which have the same tonic, the intermodulation components of the same frequency with a higher order $(p=5)$ are generated. They are the result of interaction of steps I and $\mathrm{V}$, which are common for the tonic triads with the same tonic. The "background" of the higher order combinations does not affect the identification of the major or minor keys. Obviously, in the major music the level of "background" is relatively low. The reason can be related to the fact that the order of the corresponding "background" waves is greater. Moreover, the order of dominating infrasound components is the even integer $\left(p_{k}=4\right)$, while the order of "background" infrasound waves is the odd integer $\left(p_{k}=5\right)$. The last circumstance causes an additional suppression of the "background" components.

Fig.1a illustrates the distinction of tonic triads of various major tonalities. In Fig.1a, the relationship between frequency values of the infrasound intermodulation components $(p=4)$ and tonics (with the increase of tonic frequency) is shown for the equal tempered and Pythagorean tuning.

For the equal tempered tuning, the level of the fourth order frequency components monotonically increases with an increase of the tonic frequency. For the Pythagorean tuning, this dependence is not monotonic.

For the major tonalities, the distinction of the C-sharp major (D-flat major), F-sharp major (G-flat major) and, to a lesser extent, that of the A-flat major, can be noticed. Their tonic triads are characterized by a lower frequency of the infrasound intermodulation components as compared to the corresponding triads of the other tonalities, the values of frequency being the intermediate ones for A-flat major.

For the minor tonalities of the equal tempered tuning (Fig.1b), the frequency of the infrasound components monotonically increases in the same way as for the major ones. However, the order of the intermodulation components is higher: $p=5$. For the Pythagorean tuning, this dependence is not monotonic. Here three groups can be singled out.

The first group includes the G-sharp minor (A-flat minor) and D-sharp minor (E-flat minor). For their tonic triads, the order of the infrasound components $(p=5)$ is lower (the level is higher) than for the other triads. 
The second group of the $\mathrm{F}$ minor and $\mathrm{B}$ minor is characterized by the fact that the order of the infrasound intermodulation components $(p=9)$ is much higher than for other tonalities. Accordingly, the level of these components is significantly lower.

In the third group including the remaining minor tonalities, the order of the infrasound intermodulation components is equal to 6 .

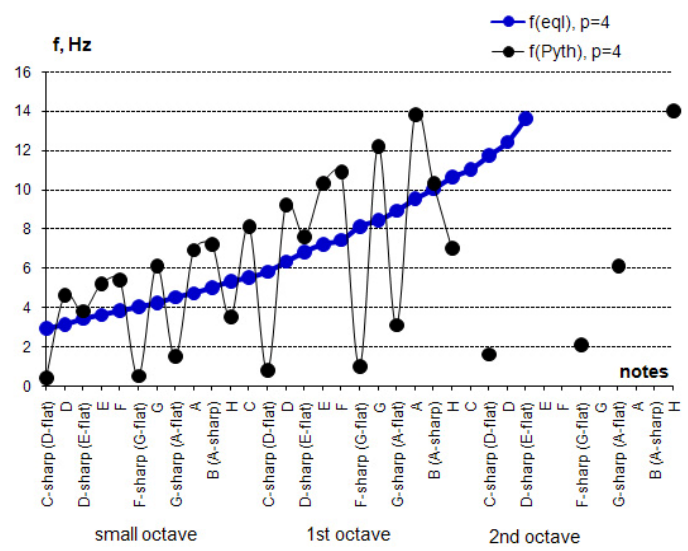

a)

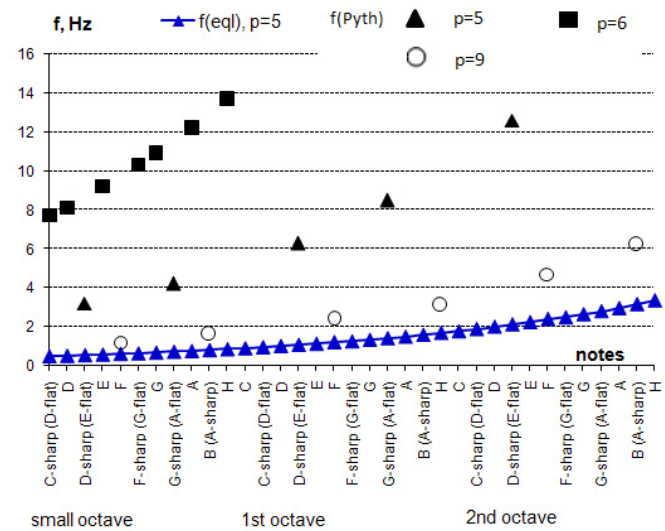

b)

Fig.1. Relationship between frequency values of the infrasound intermodulation components and tonics (with the increase of tonic frequency).

Tonic triads. Equal tempered (eql) and Pythagorean (Pyth) tuning. (The "background" components are not shown).

a) for all major tonalities $(p=4)$,

b) b) for all minor tonalities ( $p=5, p=6, p=9$ )

For the tonic thirds, some dependencies, similar to those shown in Fig.1, take place too. However, they are weaker, because the level of the corresponding infrasound intermodulation components is much lower. Also it is important what kind of tuning (the equal tempered tuning or the Pythagorean one) is applied.

The results of calculation and analysis of the well-known facts related to music perception demonstrate that:

1. The waves included in the tonic triads and thirds, interacting in the non-linear converter, cause an intermodulation product spectrum containing infrasound waves.

In the middle part of the sound scale, the major tonalities are characterized by the IFR intermodulation components of a much higher level than for the minor tonalities. The difference in emotional perception of the major and minor keys corresponds to the difference in the infrasound intermodulation component spectra.

2. The level of the IFR waves for the tonic thirds is much lower than that for the corresponding tonic triads. The biophysical premises for emotional distinction of tonic thirds are significantly weakened.

3. In the lower and higher parts of the sound scale, the difference in the IFR spectrum decreases significantly. This effect explains a "blooming" of the key colour near the sound scale boarders: in the lower part, music has a "major" hint, and in the higher part, it has a "minor" hint.

4. The range of speech sounds is practically identical to the middle part of the sound scale.

5. Since the resolution of the non-linear converter ("earbrain" system) is finite, when the volume of sound is low, the emotional difference of the major and minor keys decreases. When the sound volume grows, the difference becomes evident.

6. Within an octave, the frequency of the IFR intermodulation components depends on a tonic.

7. For the ancient Pythagorean tune, the difference between various tonalities (as used here) is significantly greater than for the equal tempered one.

8. In the equal tempered tuning, there is a common "background" of the IFR intermodulation components for both the major and minor tonic triads. Apparently, this is an additional reason why the expressiveness of the equal tempered tuning decreases in comparison with the Pythagorean one.

9. The major and minor triads are recognized by listeners not only in case when the triads are performed simultaneously (in chords), but also when they are performed consecutively [50], [55]. This proves the idea that the "ear-brain" system is characterized by a delay effect (memory). (In [56], the shortest time interval necessary to cause the emotions is estimated as $2.5-3 \mathrm{~s}$. The authors of [57] evaluate the duration of the initial (hidden) time of emotion generation as $0.15-0.30 \mathrm{~s}$. These data enable to obtain a quantitative estimate of the time delay).

\section{B. The simplest emotional images}

Identification of the emotions caused by the signal-stimuli and their ensembles should be based on statistically reliable estimates of the emotional responses of listeners.

In musicology, the tonalities are considered in accordance with their position in the circle of fifths [44-46], where the tonalities are located with an interval of 3.5 tones. The tonalities adjacent in the circle of fifths are called attendant, since a listener instinctively feels a link between them.

It should be noted that a sequence of three attendant tonic triad chords built up at steps I; IV;V, as a rule, contribute to strengthening the music expressiveness. (E.g., for the $\mathrm{C}$ major tonality, this sequence corresponds to a sequence of three tonic triads: $\mathrm{C}$ major, $\mathrm{F}$ major, and $\mathrm{G}$ major).

Statistically reliable expert judgments of a listeners' response to fragments of classical musical compositions [50] give a basis for the conclusion that the simplest emotional image is formed by the sequence of no less than three IFR 
waves which usually corresponds to the sequence of the attendant tonality chords. The images can cause a varied emotional response, e.g. contemplativeness, aloofness, or joy. When the sequence of the IFR signal-stimuli changes, a new emotional image is generated. [12].

(It is necessary to accentuate that in order for a verbal statement to be understandable, its form should be trinomial (obvious or implicit). This was noticed by the famous Russian physiologist of the 19-th century I.M. Sechenov: "For all peoples of all centuries, all tribes and all stages of intellectual growth and development, the verbal way of thinking in its simplest form is reduced to our trinomial sentence. In particular, thanks to this, we understand with an equal easiness the thoughts of an ancient man, left in written records of the past, thoughts of a savage and those of a contemporary" [58]. In [59], the significance of the trinomiality (ternarity) in the evolution is fundamentally grounded with regard to various spheres).

Fig. 2 illustrates the generation of the simplest emotional images on the basis of a sequence of chords built up at steps I; IV; V. For the Pythagorean tuning, in the small octave Fig.2, a), b), c), and d) shows the frequency and order of the intermodulation components for a number of major tonalities. The frequency and order of the intermodulation components of some minor tonalities are shown in Fig.2 e), f), g), h).

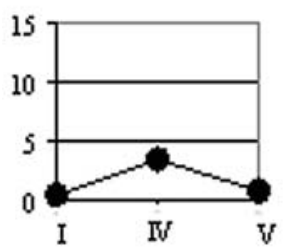

a) F-sharp major, "contemplativeness" (E. Grieg. In spring, op.43)
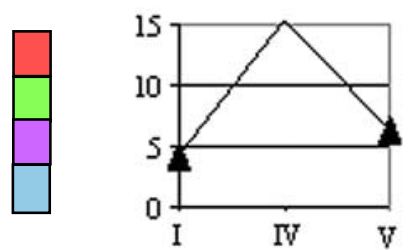

e) A-flat minor,

"aloofness"

(F. Schubert. Barcarolle, op.60)

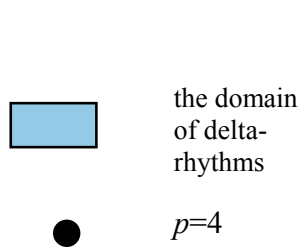

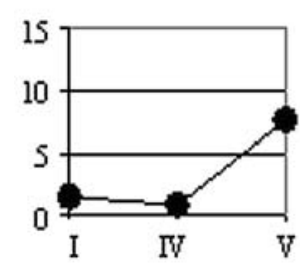

b) A-flat major,

"great energy and joyful mood" (F. Chopin. Polonaise No 6, op.53)

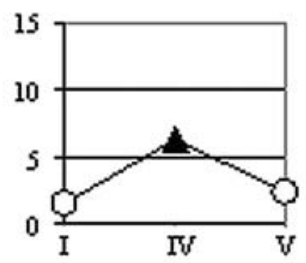

f) $\mathrm{H}$ minor,

"aloofness, transfer from mournful insensibility to tragic mood" (F. Chopin. Death march, Sonata No 2, part 3, op.35)

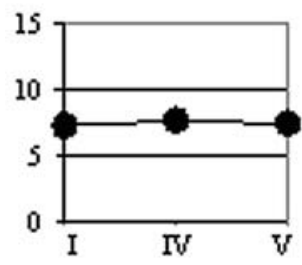

c) H major,

"energy, triumph with a transfer to calm and harmony" (F.Shubert. Ave Maria, op.32)

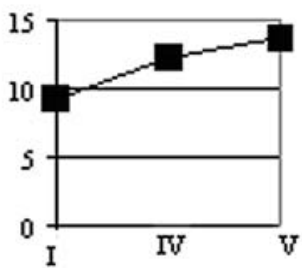

g) E minor,

"melancholy, dreaminess"

(J. Massenet. Elegy, op.10)

Signs and symbols:

\begin{tabular}{|l}
$\square$ \\
$\begin{array}{l}\text { the domain } \\
\text { of theta- } \\
\text { rhythms }\end{array}$ \\
$p=5$
\end{tabular}

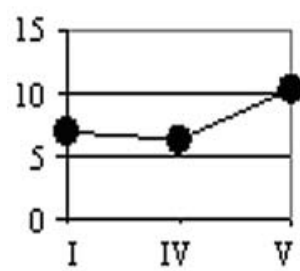

d) A major,

"happiness"

(E. Grieg. Norwegian dance, op.35)

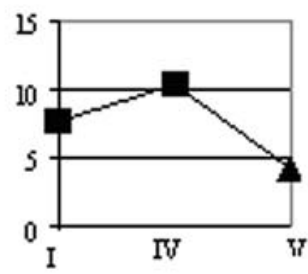

h) C sharp minor,

"fantasy, dream, transfer from a day-dream to aloofness and grief" (L. Beethoven. Sonata No 14 (Moonlight sonata), part 1, op.27)

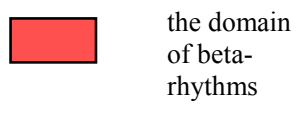

○ $\quad p=9$

Fig.2. Formation of the simplest emotional images on the basis of the sequence of chords (steps I-IV-V) in the small octave (axis of abscissa is frequency $f, \mathrm{~Hz}$, ordinate axis is a step number).

It is interesting that the character of the functions presented in the space of biorhythms, enables to judge about the emotional colour of an image.

Between the emotional response to graphical representation of the emotional images shown in Fig.2 and the emotional response to the corresponding musical fragments, some correlation can be noticed. Rising of the curves corresponds to a hope for something better, as well as to a joyful mood. "Dipping" of the curves is associated with expectation of some bad mood. The perception is influenced by steepness of the curve rising and "dipping". To all appearance, this correlation is caused by similarity of the models of acoustical and visual impact perception.

\section{Relationships between signal-stimuli frequencies and emotional image being formed}

Further detailing of the measurement model requires revealing a relationship between signal-stimuli parameters and emotions. One of the objects to be studied is the field, where the spectrum of the simplest emotional images has a bright and clear emotional colour. Therefore, at the new stage of investigation, a special consideration was given to 
the analysis of ethnic and ancient religious music with a known mood.

With that end in view, at the D.I. Mendeleyev Institute for Metrology, software "Music 1.0" intended for analyzing sound files of wav-format, was developed. Software includes a virtual four-pole network, the conversion function of which is described by a polynomial of the power that is not higher than 11. A power of the polynomial, coefficients of the latter " $k$ ", as well as measurement time and delay time are set by a user. The measurement time should be less than a half of the input signal duration.

Software enables to calculate the spectrum of input and output data by executing the Fourier-transform. The latter provides visualization of frequency decomposition of a complicated stationary signal into the simplest wave functions. The frequency range of the spectrum analyzed at the output of the four-pole network can be adjusted within a wide range.

With the help of the above version of software, we analyzed the fragments of African ethnic music (GUEM) with the specific titles "Festival", "Fear", and "Nightmare", performed on drums and recorded as wav-files. Fig.3 shows the IFR spectra at the four-pole network output.

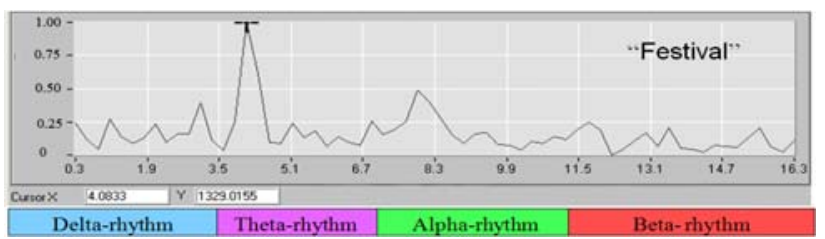

a)

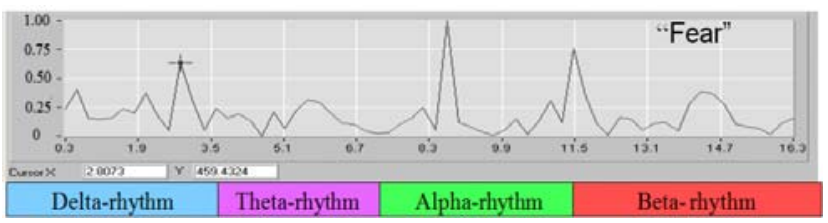

b)

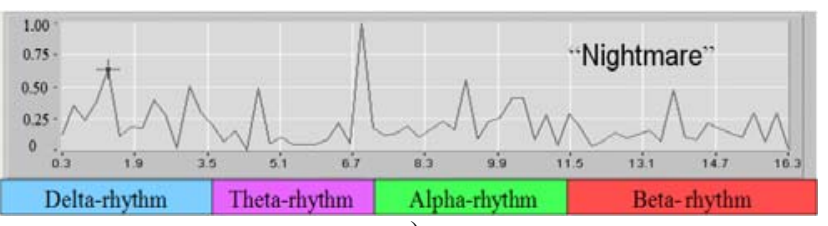

c)

Fig.3. Spectra of the IFR intermodulation components after nonlinear conversion of the input data

(axis of abscissa is the frequency, Hz; ordinate axis is the level of spectrum components determined in conventional units).

a) "Festival", b)"Fear", c) "Nightmare"

As the spectrum of the drum sound lies in the band of low frequencies, for a greater obviousness, the conversion function was assumed as the quadratic one $(k=2)$. The measurement time was set to approximately $4 \mathrm{~s}$.

An opportunity for measuring the emotions contained in music fragments is illustrated by examples given below. Fig.3 demonstrates the difference of the IFR wave spectra and a small number of maximums (signal-stimuli) in these spectra which determine an expected emotional response of listeners.

To reveal the emotional content of the images, it is necessary to analyze the relationship between the frequency values of the IFR maximums and biorhythm frequencies.

A minimum frequency of a signal-stimulus for the fragment "Festival" is close to $4 \mathrm{~Hz}$, which corresponds to the domain of theta-rhythms; for the "Fear" the minimum frequency decreases approximately to $2.8 \mathrm{~Hz}$, passing into the domain of delta-rhythms; for the fragment "Nightmare" it falls down and becomes less than $2 \mathrm{~Hz}$.

The "Festival" is characterized by a comparatively low level of maximums in the band of the 2nd and 3rd harmonics of the signal-stimuli (the domain of alpharhythms). At the same time, these maximums are smooth.

The spectra generated by the "Fear" and especially by the "Nightmare" contain an increased number of maximums, which are sharper than for the "Festival".

For the "Fear":

- in the range of the $2^{\text {nd }}$ harmonic of a signal-stimulus (in the domain of theta - rhythms), the maximum is "blurred",

- in the range of the $3^{\text {rd }}$ and $4^{\text {th }}$ harmonics (in the domain of alpha - rhythms), the maximums are higher than the $1^{\text {st }}$ one.

- even in the range of the $5^{\text {th }}$ harmonic (in the domain of beta - rhythms) the value of the maximum and square under it are close to those for the $1^{\text {st }}$ harmonic.

The "Nightmare" generates noticeable maximums near the 2nd and 3rd harmonics of the signal-stimulus (in the domain of delta-rhythms), some peaks (including the highest one near $7 \mathrm{~Hz}$ ) in the domain of theta-rhythms, and significant maximums in the domains of alpha- and beta-rhythms.

The relationship between activated brain biorhythms and a state of a wakeful man is shown in Table 1.

Information given in Table 1 is in good agreement with the data of the IFR spectrum analysis (Fig.3). The analysis shows that the frequency of a signal-stimulus determines the basic emotion. When the signal-stimulus appears in the domain of delta-rhythm frequency, the mood of a listener becomes anxious. The less the frequency of the signalstimulus, the higher is the level of an expected danger.

Combination of a signal-stimulus and additional components of the frequency spectrum generates an emotional image. Stress mobilizes attention and muscular activity, which are proved by a significant increase of the level of alpha- rhythm and, to a lesser extent, of betarhythm ("Fear").

Uncertainty of an anxiety source together with feelings of the increased danger ("Nightmare"), intensify the search of recollections and associations which could be used to develop an activity program. This is shown by a rise of the level of waves in the domain of theta-rhythms. The spectrum peaks in the domain of alpha- and beta-rhythms are smoothed, cover smaller areas and have a lower level. This demonstrates that the program of listeners' activities has not been found.

The emotion related to the "Festival" reflects the recollections of bygone successes and gives an associative hope for future victories, which is stimulated by a signal of the theta-rhythm frequency. At the same time, the level of 
attention to environmental conditions and mobilization of muscular activity are at the background (usual) level.

The examples given prove the opportunity to decode the emotional content of music fragments, under the influence of which a number of the IFR signals are generated practically at the same time.

Moreover, decoding of the mood influenced by each signal-stimulus enables to develop the above estimates of the emotional content of the simplest images caused by the sequence of tonic triads (Fig.2). Examples of the emotional content of the simplest images are given in Table 2.

Table 1. State of a wakeful man and activated brain biorhythms

\begin{tabular}{|c|c|l|}
\hline $\begin{array}{c}\text { Bio- } \\
\text { rhythm }\end{array}$ & $\begin{array}{c}\text { Frequency range, } \\
\mathrm{Hz}\end{array}$ & \multicolumn{1}{|c|}{ State of a wakeful man } \\
\hline $\begin{array}{c}\text { Delta- } \\
\text { rhythm }\end{array}$ & $0.5-3.5$ & $\begin{array}{l}\text { Interest of a man in something; some } \\
\text { types of a stress; increase of hormone } \\
\text { production, which contributes to } \\
\text { physical reconditioning }\end{array}$ \\
\hline $\begin{array}{c}\text { Theta- } \\
\text { rhythm }\end{array}$ & $4.0-7.5$ & $\begin{array}{l}\text { Generation of bright images, } \\
\text { recollections, and unexpected } \\
\text { associations }\end{array}$ \\
\hline $\begin{array}{c}\text { Alpha- } \\
\text { rhythm }\end{array}$ & $8.0-11.5$ & $\begin{array}{l}\text { Improvement of sensibility, sharp } \\
\text { increase of muscular activity }\end{array}$ \\
\hline $\begin{array}{c}\text { Beta- } \\
\text { rhythm }\end{array}$ & $12.0-29.5$ & $\begin{array}{l}\text { Intensification of attention, mental } \\
\text { strain, emotional excitement }\end{array}$ \\
\hline
\end{tabular}

Table 2 Examples of emotional content of the simplest images

\begin{tabular}{|c|c|c|}
\hline Tonality & $\begin{array}{l}\text { Mood according to } \\
{[50]}\end{array}$ & $\begin{array}{l}\text { Mood according to results of the } \\
\text { biorhythm analysis }\end{array}$ \\
\hline $\begin{array}{l}\text { F-sharp } \\
\text { major }\end{array}$ & Contemplativeness & $\begin{array}{l}\text { Recollections and associations } \\
\text { with the background of a deep } \\
\text { grief }\end{array}$ \\
\hline $\begin{array}{l}\text { A-flat } \\
\text { major }\end{array}$ & $\begin{array}{l}\text { Great energy and } \\
\text { joyful mood }\end{array}$ & Hope on some better after tragedy \\
\hline $\mathrm{H}$ major & $\begin{array}{l}\text { Energy, triumph with a } \\
\text { transfer to calm and } \\
\text { harmony }\end{array}$ & $\begin{array}{l}\text { Pleasant recollections and } \\
\text { associations }\end{array}$ \\
\hline A major & Happiness & $\begin{array}{l}\text { Bright associations accompanied } \\
\text { by a wish to intensify muscular } \\
\text { activity }\end{array}$ \\
\hline $\begin{array}{l}\text { A-flat } \\
\text { minor }\end{array}$ & Aloofness & $\begin{array}{l}\text { Vague recollections (the level of } \\
\text { the IFR components is low, but it } \\
\text { is the highest one for the minor } \\
\text { tonalities) }\end{array}$ \\
\hline H minor & $\begin{array}{l}\text { Aloofness, transfer } \\
\text { from mournful } \\
\text { insensibility to tragic } \\
\text { mood }\end{array}$ & $\begin{array}{l}\text { Feeling of tragedy after vague } \\
\text { recollections (the level of IFR } \\
\text { components is the lowest) }\end{array}$ \\
\hline E minor & $\begin{array}{l}\text { Melancholy, } \\
\text { dreaminess }\end{array}$ & $\begin{array}{l}\text { The mood corresponds to the } \\
\text { interpretation of [50] }\end{array}$ \\
\hline $\begin{array}{l}\text { C-sharp } \\
\text { minor }\end{array}$ & \begin{tabular}{|l|}
$\begin{array}{l}\text { Fantasy, dream, } \\
\text { transfer from a day- } \\
\text { dream to aloofness and } \\
\text { grief }\end{array}$ \\
\end{tabular} & $\begin{array}{l}\text { The mood corresponds with the } \\
\text { interpretation of [50] }\end{array}$ \\
\hline
\end{tabular}

\section{DISCUSSION}

The above information proves that the proposed measurement model can be applied to the "fuzzy" measurements of the emotions contained in music fragments.
In the last decades, a special technology of mental audio guidance (Hemi-Sync), developed and patented by Mr. R. Monroe, has been comprehensively discussed. This technology is based on the linear conversion of waves (on the so called "binaural effect "), i.e. on the perception of "non-existent" sounds generated by beatings of acoustic waves, which are perceived by each ear separately [60]. The technology effectiveness is explained by a directed stimulation of the brain, which is performed at coincidence of the binaural beating frequency with the frequency of brain biorhythms.

The acoustic beating impact on the state of a listener agrees with the above hypothesis. However, the above explanation of the emotions contained in acoustic fragments by the binaural effect only, is at variance with the fact that music excites even those listeners, one ear of whom has been injured. Moreover, the binaural effect does not explain the variety of emotional responses to acoustic impacts.

The model developed by the authors enables to create a special measuring instrument that will make it possible to evaluate the "emotionality" of music without bias. The scale of such an emotion measuring instrument is multiparametric. Each emotional image should be estimated on the basis of a combination of several IFR wave parameters, measured at adjacent time intervals. The method of constructing this scale is illustrated by the above examples. If a sequence of the IFR signal-stimuli changes, a new emotional image is generated. Its colour depends on a previous and/or subsequent emotional image.

A sequence of the simplest emotional images determines the emotional content of a musical fragment. It is natural, that identification of the emotions generated by the music fragments played backward, is disturbed. It is typical for both representatives of Western culture and listeners from an ethnic group called Mafa (Cameroon) [61].

It should be emphasized, that the main simplest emotional images depend on the biological background developed in the process of evolution. Therefore, the emotional response of people with healthy psyche, who are in a balanced state of mood, to these signal-stimuli and images has to be characterized by a sharp peak of its distribution irrespective of the culture these people belong to.

This statement is confirmed by the investigations [49], [61].

The possibility to apply the same approach to decoding the fragments of African ethnic music and harmonic tonal music shows that this approach is a universal tool for measuring the emotions generated by music of various types.

From the above it follows that the type A evaluation of measurement uncertainty mainly depends on the health state and mood of "testees". The psyche of listeners is also under the influence of external factors, such as colour and illumination of premises, unwanted sounds or noises, etc.

To decrease the uncertainty, it is useful to perform a preliminary emotional adjustment of "testees", i.e. to remove their intrinsic stress, prepare them to an experiment and so on [62]. Essentially, an overture performed before an opera serves the same purpose. 
A stable deviation of the emotional response to the signalstimuli from a typical one, can be the indicator of an unhealthy mental state of a person.

The response to more complicated acoustic impacts has been developed at comparatively later stages of evolution and depends, to a great extent, on cultural traditions of listeners and on their psychotype.

The type B measurement uncertainty is determined, mainly, by the fact that the unified and consistent theory of emotion scales has not yet been developed.

In fundamental works on psychology of emotions, their nature and functions [8] and [63], accordingly, it is shown that there are significant difficulties in the development of an unambiguously determined scale of emotions.

The type B measurement uncertainty increases due to incompleteness of knowledge of the role the brain biorhythms play in mental activity. Even the frequency limits of biorhythm domains are differently estimated in literature.

Evidently, if the frequency values of the IFR intermodulation components are close to the boundaries of biorhythm frequency domains, then the uncertainty of the emotional response increases.

The results presented above do not contradict experimental data given in [49], [64] - [68].

\section{CONCLUSIONS}

To improve the traceability of "fuzzy" measurements in the field of humanities, it is expedient to develop measurement models with a minimum number of parameters to be measured, each of them having a reference for comparison. Such an approach corresponds to the definition of measurability of objects, suggested in [69].

The most efficient way to develop the models of this type is to apply physical, biological, sociological, economical or other regularities (depending on the field of measurements) in them. It is shown that the development of these models can be facilitated with the help of an evolutionary analysis.

In this case, the measurement procedure is similar to "strongly defined measurements" [2].

The suggestions given are grounded by example of the model for making "fuzzy" measurements of expected emotional responses to musical or other acoustic fragments.

\section{ACKNOWLEDGMENT}

The authors of this paper are grateful to Dr. V. Elkin for active participation in discussions and Dr. A. Pepelyshev for development of the computer program.

\section{REFERENCES}

[1] Finkelstein, L. (2003). Widely, strongly and weakly defined measurement. Measurement, 34 (1), 39-48.

[2] Finkelstein, L. (2008). Problems of widely-defined measurement. In Proceedings of the 12th IMEKO TC1 \& TC7 Joint Symposium on Man Science \& Measurement, 3-5 September 2008. Annecy, France: LISTIC, 23-29.
[3] Rossi, G.B., Berglund, B. (2009). Measurement related to human perception and interpretation - state of the art and challenges. In Proceedings of the XIX IMEKO Congress on Fundamental and Applied Metrology, 611 September 2009. Lisbon, Portugal, 1164-1169.

[4] Goodman, T., Montgomery, R. et al. (2008). The measurement of naturalness. In Proceedings of the 12th IMEKO TC1 \& TC7 Joint Symposium on Man Science \& Measurement, 3-5 September 2008. Annecy, France: LISTIC, 31-36.

[5] Miekina, A., Morawski, R.Z. (2009). A flexible experimental set-up for development of spectrophotometric analysers of food. In Proceedings of the XIX IMEKO Congress on Fundamental and Applied Metrology, 6-11 September 2009. Lisbon, Portugal, 2565-2573.

[6] MINET: Measuring the Impossible NETwork. http://www.measuringimpossible.net

[7] International Vocabulary of Metrology - Basic and General Concepts and Associated Terms (VIM). (2008). JCGM - Joint Committee for Guides in Metrology.

[8] Izard, C.E. (1991). The Psychology of Emotions. Springer US.

[9] Sapozhnikova, K., Taymanov, R. (2001). Biophysical premises for developing measurement model of perceiving structural elements of music. In Proceedings of International Conference on Theory, Methods, and Measuring Instruments, 21 September 2001. Novocherkassk, Russia: URGTU, 59-65.

[10] Sapozhnikova, K., Taymanov, R. (2003). About a measuring model of emotional perception of music. In Proceedings of the XVII IMEKO World Congress, 2227 June 2003. Dubrovnik: Croatian Metrological Society, 2049-2053.

[11] Sapozhnikova, K., Taymanov, R. (2008). Measurement of the emotions in music fragments. In Proceedings of the 12th IMEKO TC1 \& TC7 Joint Symposium on Man Science \& Measurement, 3-5 September 2008. Annecy, France: LISTIC, 75-80.

[12] Sapozhnikova, K., Taymanov, R. (2009). Improvement of traceability of widely-defined measurements in the field of humanities. In Proceedings of the ISMTII'2009, 29 June - 2 July 2009. St. Petersburg, Russia, 4-239- 4-243.

[13] Sapozhnikova, K., Taymanov, R. (2009). Multiparametric measurements of emotions. In Proceedings of the XIX IMEKO Congress on Fundamental and Applied Metrology, 6-11 September 2009. Lisbon, Portugal, 1180-1185.

[14] Savelyev, S.V. (2005). Origination of the Brain. Moscow: VEDI.

[15] Altman, J. (ed.) (1990). Auditory system. Leningrad: Nauka.

[16] Muller, J., Tsuji, L.A. (2007). Impedance-matching hearing in paleozoic reptiles: evidence of advanced sensory perception at an early stage of amniote evolution. PLoS One, 2 (9), e889. 
[17] Manley, G.A., Popper, A.N., Fay, R.R. (eds.) (2004). Evolution of the Vertebrate Auditory System (Springer Handbook of Auditory Research). New York: Springer-Verlag.

[18] Horbenko, I. (1978). Sound, Infra- and Ultra-sounds. Moscow: Znanie.

[19] Arends, B., Thackara, D. (eds.) (2004). Experiment: Conversations in Art and Science. The Wellcome Trust.

[20] Cody, J.D. (1997). Infrasound. http://journal.borderlands.com/1997/infrasound/

[21] Irvine, T. (2005). Elephant infrasound. http://www.vibrationdata.com/Newsletters/February20 05_NL.pdf

[22] National Toxicology Program (2001). Infrasound: brief review of toxicological literature (Infrasound toxicological summary November 2001). http://ntp.niehs.nih.gov/ntp/htdocs/Chem_Background/ ExSumPdf/Infrasound.pdf

[23] Todd, N.P.M., Rosengren, S.M., Colebatch, J.G. (2008). Tuning and sensitivity of the human vestibular system to low-frequency vibration. Neuroscience Letters, 444 (1), 36-41.

[24] Kaczmarska, A., Uczak, L. (2008). Analysis of annoyance caused by infrasound and low-frequency noise during mental work. Archives of Acoustics, 33 (3), 331-340.

[25] Yuan, H., Long, H., Mou, X. (2008). The effect of $8 \mathrm{~Hz}$ infrasound on the learning and memory ability and proliferation in rats' brain. Chinese Journal of Rehabilitation Medicine, 23 (5), 385-387.

[26] Seabrook, W. (1941). Doctor Wood: Modern Wizard of the Laboratory. New York: Harcourt, Brace and company.

[27] Volodin, I.A., Volodina E.V. et al. (2009). Indicators of emotional arousal in vocal emissions of the humans and nonhuman mammals. Journal of General Biology, 70 (3), 210-224.

[28] Jurgens, U. (1979). Vocalization as an emotional indicator: a neuroethological study in the squirrel monkey. Behaviour, 69 (1-2), 88-117.

[29] Dolnik, V.R. (2003). Indocile Child of Biosphere (3rd ed.). St. Petersburg: CheRo-na-Neve Press.

[30] Mithen, S. (2009). The music instinct: the evolutionary basis of musicality. Annals of the New York Academy of Sciences, 1169, 3-12.

[31] Kroupa, V.F. (1973). Frequency Synthesis: Theory, Design \& Application. C. Griffin \& Co Ltd.

[32] Kroupa, V.F. (2003). Phase Lock Loops \& Frequency Synthesis. Wiley.

[33] Wikipedia: Intermodulation. http://en.wikipedia.org/wiki/Intermodulation

[34] Butler, L. VK5BR (first published in "Amateur Radio" 1997). Intermodulation performance and measurement of intermodulation components, http://users.tpg.com.au/users/ldbutler/Intermodulation. htm
[35] Pongracz, P., Miklosi, A., Molnar, C., Csanyi, V. (2005). Human listeners are able to classify dog (Canis familiaris) barks recorded in different situations. Journal of Comparative Psychology, 119 (2), 136-144

[36] Blumstein, D.T., Armitage, K.B. (1997). Alarm calling in yellow-bellied marmots: I. The meaning of situationally specific calls. Animal Behaviour, 53, 143-171.

[37] Pongracz, P., Molnar, C., Miklosi, A. (2006). Acoustic parameters of dog barks carry emotional information for humans. Applied Animal Behaviour Science, 100 (3-4), 228-240.

[38] Linnankoski, I., Laakso, M. et al. (1994). Recognition of emotions in macaque vocalization by children and adults. Language \& Communication, 14 (2), 183-192.

[39] Aldoshina, I. Pritts, R. (2006) Musical Acoustics, St. Petersburg: Kompozitor.

[40] Schulter, M. (1998). Pythagorean tuning and medieval polyphony. http://www.medieval.org/ emfaq/harmony/pyth2.html

[41] Voloshinov, A.V. (1992). Mathematics and Art. Moscow: Prosveschenie.

[42] Schmidt-Jones, C.: Tuning systems. http://cnx.org/content/m11639/latest/

[43] Vurma, A., Ross, J., Ogorodnikova, E. (2006). Perception of vocal musical intervals. Sensornye sistemy, 20 (2), 117-125.

[44] Encyclopedia Britannica Online. http://www.britannica.com/

[45] Sadie, S., Tyrrell, J. (2001). The New Grove Dictionary of Music and Musicians (2nd edition). London: Macmillan Publishers.

[46] Sposobin, I. (1959). Elementary Theory of Music. Moscow: Musgiz.

[47] Ewer, G.: Easy Music Theory. Lesson 10: intervals. http://www.musictheory.halifax.ns.ca/ 10intervals.html

[48] Ewer, G.: Easy Music Theory. Lesson 15: tonic and dominant triads. http://www.musictheory. halifax.ns.ca/15tdt.html

[49] Oelmann, H., Laeng, B. (2009). The emotional meaning of harmonic intervals. Cognitive Processing, 10 (2), 113-131.

[50] Elkin, V. (2000). Curative (Medical) Magic of Music: Harmony of Colour and Sound in Therapy of a Disease. St. Petersburg: Respeks.

[51] Wikipedia: Tonality. http://en.wikipedia.org/wiki/Tonality

[52] Taymanov, R. (1977). Calculation of the amplitude spectrum of combination waves. Non-linear distortions in receiving-amplifying devices. In Proceedings of the First All-union Symposium. Minsk: MRI, 43-45.

[53] Taymanov, R. (1961). Calculation of frequency converters. Voprosy radioelectronicy, 10 (1), 127-135.

[54] Taymanov, R. (1961). Calculation of side combination frequencies. Voprosy radioelectronicy, 10 (3), $138-148$ 
[55] Varyagina, O., Brattico, E. et al. (2004). Brain responses to dissonant and mistuned and not mistuned but non minor triads differ between musicians and nonmusicians. In Proceedings of the 8th International Conference on Music Perception \& Cognition, 3-7 August 2004. Adelaide, Australia: Causal Productions, 808-811.

[56] Guzikov, B.M., Altman, J.A. et al. (2004). Perception of short musical fragments in humans. Sensornye sistemy, 18 (3), 239-250.

[57] Varyagina, O., Khromatidi, A. et al. (2006). The mismatch negativity as an index of changing the tonal schema of chord progressions. Sensornye sistemy, 20 (3), 180-186.

[58] The Monroe Institute (2009). What are binaural beats? http://www.monroeinstitute.org/hemi-sync/what-arebinaural-beats/

[59] Sechenov, I.M. (1953). About Objective Thought from the Physiological Point of View. Selected Papers. Moscow.

[60] Petrov, V.M. (2008). Ternarity in thought, culture, and arts: system-informational origins of unconsciousness. Psycology: Journal of Higher School of Economics, 5 (4), 3-18

[61] Fritz, T., Jentschke, S. et al. (2009). Universal recognition of three basic emotions in music. Current Biology, 19 (7), 573-576.
[62] Sapozhnikova, K., Taymanov, R., Elkin, V. (2004). The procedure of measurements for discovering regularities of relationships between music and color. In Proceedings of the 2nd International Symposium on Measurements, Analysis and Modeling of Human Functions, 14-16 June 2004. Genova, Italy: University of Genova, 391-395.

[63] Golitsyn, G.A. (1997). Information and Creativity. Moscow: Russkiy Mir.

[64] Ivanchenko, G.V. (2001). Psycology of Music Perception: Approaches, Problems, Perspectives. Moscow: Smysl.

[65] Webster, G.D., Weir, C.G. (2005). Emotional responses to music: interactive effects of mode, texture, and tempo. Motivation and Emotion, 29 (1), 19-39.

[66] Nardi, B., Arimatea, E. et al. (2005). Cortical analysis of music piece in musicians and non-musicians. Rivista di Psichiatria, 40 (2), 40-92.

[67] Hailstone, J.C., Omar, R. et al. (2009). It's not what you play, it's how you play it: timbre affects perception of emotion in music. Quarterly Journal of Experimental Psychology, 62 (11), 2141-2155.

[68] Nishifuji, S., Miyahara, I. (2008). Destabilization of alpha wave during and after listening to unpleasant and pleasant acoustic stimuli. In Proceedings of the SICE Annual Conference, 20-22 August, 2008. Tokyo: The University Electro-Communications, 2732-2737.

[69] Rossi, G.B (2007). Measurability. Measurement, 40 (6), 545-562. 